\title{
The language of science
}

\author{
Sibusiso Biyela, science communicator and journalist in South Africa, talks to Nature Chemistry about the \\ decolonization of science through science communication.
}

\section{What are you working on at the moment?}

I am involved in quite a number of projects that I am proud to be a part of that have come about through my advocacy for the decolonization of science - which encompasses work to deconstruct the legacies of the field's colonial past, still prevalent today - through science communication. I'm currently consulting on and creating content for a new museum exhibit that will tell the story of human evolution from the perspective of Africans. I'm also helping train a natural language-processing algorithm to translate scientific terms into six African languages, all based on research conducted in Africa.

The 'Masakhane MT: Decolonise Science' project will translate 180 African research articles to create a machine translation tool for six African languages. I am the science communication partner on the project, and I consult on decolonization to make sure the translations serve the needs of the African language speakers.

It's been a busy year and a half since the start of the pandemic, with many speaking engagements that I gave online. These have included talks about decolonization at many conferences from gatherings of Black paleoanthropologists, a meeting of plain-language professionals in finance, health and law from all over the world, a panel discussion on decolonizing human evolution science, a conference on the history of science, and a panel discussion on how scientists can better engage with the media.

Can you tell us about your background - how did you get interested in science and science communication?

I started from a very young age enjoying science-based programmes on TV. They were all I wanted to watch and I took every opportunity to watch as many of them as I could find. My mother encouraged me to read a lot, so I frequented the local public library quite often and I always checked out the maximum number of books. Being a socially awkward kid growing up, science felt like the only thing about the world that made sense to me; I was never bored of learning new things about the universe.

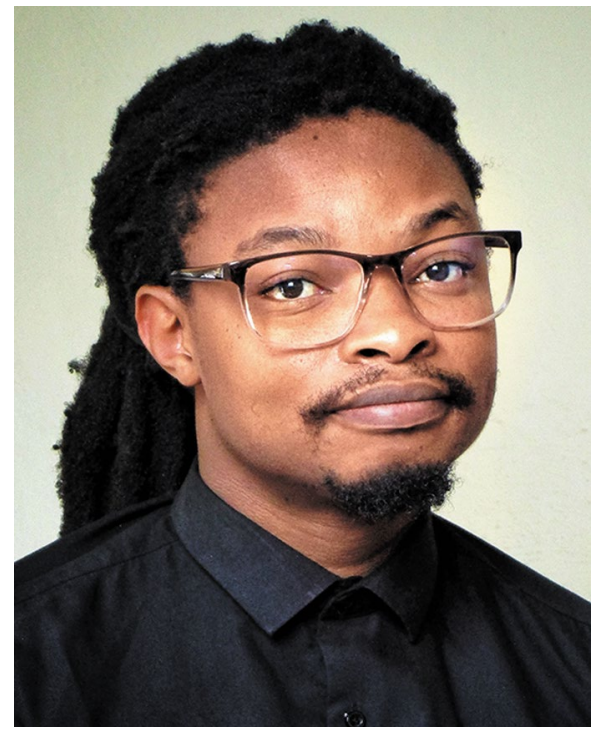

in your own language makes it easier to culturally own science and take with it the many benefits it brings to our lives. My efforts, and those of many others translating science in South Africa, have already sparked new interest in science and how it is communicated. They have also highlighted the history of Apartheid in South Africa in denying Black South Africans adequate education in science, and its persisting legacy.

\section{What are some of the main challenges you encountered?}

One of the challenges I faced early on was when I interviewed a former university classmate of mine for a profile piece about her work in particle physics. We're both quite knowledgeable in chemistry and interested in discussing the elements and particles, but we had such a hard time talking about them in simple terms in

I took up science subjects at school and at university, where I carried out my undergraduate studies in chemistry and physics. Over time my love for explaining science to my friends and family evolved into a career in science communication. I worked as a journalist for a while, learning the ropes of the media, communication and how to write, until I became a full-time science communicator and part-time science journalist.

I've always loved science, not only for all the knowledge it possesses but even more so for the skills it teaches, such as critical thinking, problem solving and how to make sense of a 'demon-haunted world' full of misinformation and magical thinking.

\section{Why did you start writing about} science in your native language, isiZulu? I've always found it troubling that I can speak to my close friends and family about a whole host of topics about the world in my mother tongue, isiZulu, but I am forced to switch to English when talking about science. I'm quite good at explaining science concepts to non-scientists but I find that I reach my limits quickly when doing so in my home language.

The issue here is not that the people I'm communicating with cannot speak or understand English, but that I think knowing, or simply discussing, science
isiZulu that a lot of our conversation ended up being in English instead.

I'd initially pitched the story to my editor as a Zulu-based piece so you can imagine my disappointment when that didn't end up happening the way I wanted. The problem wasn't so much a failure between science enthusiasts wanting to talk about science for a lay audience, but that we wanted to talk about concepts for which the scientific terms did not exist in our language.

That didn't sit well with me, and it still doesn't, but I have hope that this is slowly changing in South Africa. I've had better luck talking about dinosaurs and palaeontology in general - and I'm also looking forward to expanding the Zulu science lexicon through some of the projects I am working on.

Beyond removing language barriers, how can science communication help to address issues created in the scientific field by the country's colonial past? In one of my most cited articles on the topic (Biyela, S. Decolonizing Science Writing in South Africa. The Open Notebook; 2019), I quote a prominent sociology professor and avid proponent for the decolonization of knowledge, Kwesi Kwaa Prah, where he says that science literacy is important for Africans to be able to create the innovations that knowledge in science and technology 
allows. I believe in that important idea and add that understanding science in one's own language can only make it easier to trust the institution of science - this is particularly important in times of misinformation.

Science has been used in the past to cause great harm to vulnerable populations, and history is peppered with examples that would make any Black person wary of it. Science has been misused in South Africa in so many ways that trust in it can be very low among Black people. Even though the Apartheid government fell in 1994, the many barriers it had put in place still play a role in how people see science.

I think science communication that recognizes these issues, and validates the feelings of people who have been affected by them negatively, can go a long way to reaching the people that need science the most. Right now, South Africa needs it more than ever because there is an alarming amount of vaccine hesitancy at a time when COVID-19 infection rates continue to break records.

What are your plans for the future?

I'd like to continue with the projects I am working on at the moment and make science content in isiZulu and other indigenous languages in South Africa more mainstream; I can be found on Twitter (@AstroSibs) discussing some of these endeavours. I am interested in the history of science and how we talk about it today through a decolonized lens so I'd want to study that in a postgraduate capacity in science communication.

There might be a book in the pipeline if my study plan goes accordingly and hopefully I can report in it the many positive successes brought about by the growing movement to decolonize science and science communication in South Africa and the rest of the world.

Interviewed by Anne Pichon

Published online: 26 October 2021 https://doi.org/10.1038/s41557-021-00822-y 